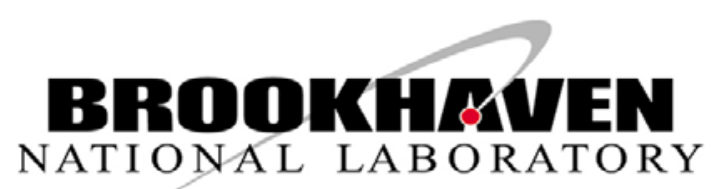

BNL-113408-2017-JA

\title{
Chloromethane to olefins over H-SAPO-34: Probing the hydrocarbon pool mechanism
}

\author{
Dustin W. Fickel, Kaiwalya D. Sabnis, Luanyi Li, \\ Neeta Kulkarni, Lea R. Winter, Binhang Yan, Jingguang G. Chen
}

Submitted to Journal of Applied Catalysis A-General

October 2016

Chemistry Department

Brookhaven National Laboratory

\author{
U.S. Department of Energy \\ USDOE Office of Science (SC), \\ Basic Energy Sciences (BES) (SC-22)
}




\section{DISCLAIMER}

This report was prepared as an account of work sponsored by an agency of the United States Government. Neither the United States Government nor any agency thereof, nor any of their employees, nor any of their contractors, subcontractors, or their employees, makes any warranty, express or implied, or assumes any legal liability or responsibility for the accuracy, completeness, or any third party's use or the results of such use of any information, apparatus, product, or process disclosed, or represents that its use would not infringe privately owned rights. Reference herein to any specific commercial product, process, or service by trade name, trademark, manufacturer, or otherwise, does not necessarily constitute or imply its endorsement, recommendation, or favoring by the United States Government or any agency thereof or its contractors or subcontractors. The views and opinions of authors expressed herein do not necessarily state or reflect those of the United States Government or any agency thereof. 


\title{
Chloromethane to Olefins over H-SAPO-34: Probing the Hydrocarbon Pool Mechanism
}

\author{
Dustin W. Fickel ${ }^{a^{*}}$, Kaiwalya D. Sabnis ${ }^{a}$, Luanyi Li ${ }^{a}$, Neeta Kulkarni ${ }^{a}$, Lea R. Winter ${ }^{b}$, Binhang Yan ${ }^{c}$, \\ Jingguang $G$. Chen ${ }^{\mathrm{b}, \mathrm{c}}$ \\ ${ }^{a}$ SABIC Technology Center, Sugar Land, TX, USA 77478 \\ ${ }^{b}$ Department of Chemical Engineering, Columbia University, New York, NY, USA 10027 \\ cChemistry Department, Brookhaven National Laboratory, Upton, NY, USA 11973 \\ *Corresponding Author: dfickel@sabic.com
}

\begin{abstract}
By means of in situ FTIR and ex situ ${ }^{13} \mathrm{C}$-NMR studies, the initial periods of the chloromethane-to-olefins (CTO) reaction over SAPO-34 were probed in order to investigate the activation period of the reaction and to elucidate the formation of the catalyst active site. A methylated benzene species has been observed to form during the initial activation period of the reaction, and a direct positive correlation was constructed between the formation of this species and the catalytic activity. The data thus indicate that these methylated benzene species contribute to the formation of active sites within SAPO-34 for the СТО reaction. This is the first known report identifying a direct semi-quantitative correlation between the catalyst activity and growth of a methylated benzene active species, during the activation period of the chloromethane to olefins reaction. The findings herein correspond well to those reported for the methanol to olefins reaction, suggesting that a similar 'hydrocarbon pool' mechanism may be responsible for the formation of light olefins in СTO chemistry as well.
\end{abstract}




\section{Highlights}

- Gradual formation of methylated benzene species during the initial stages of the chloromethane to olefins reaction is confirmed using ex situ ${ }^{13} \mathrm{C}-\mathrm{NMR}$ and in situ FTIR.

- Direct correlation between chloromethane conversion and concentration of methylated aromatics during induction period.

- Extrapolation of methanol-to-olefins hydrocarbon pool mechanism to the chloromethane-toolefins (CTO) reaction.

- Loss of micropore volume by carbon-filling suggests that the deactivation of SAPO-34 during the СTO reaction proceeds through the growth of polyaromatics.

\section{Graphical Abstract}

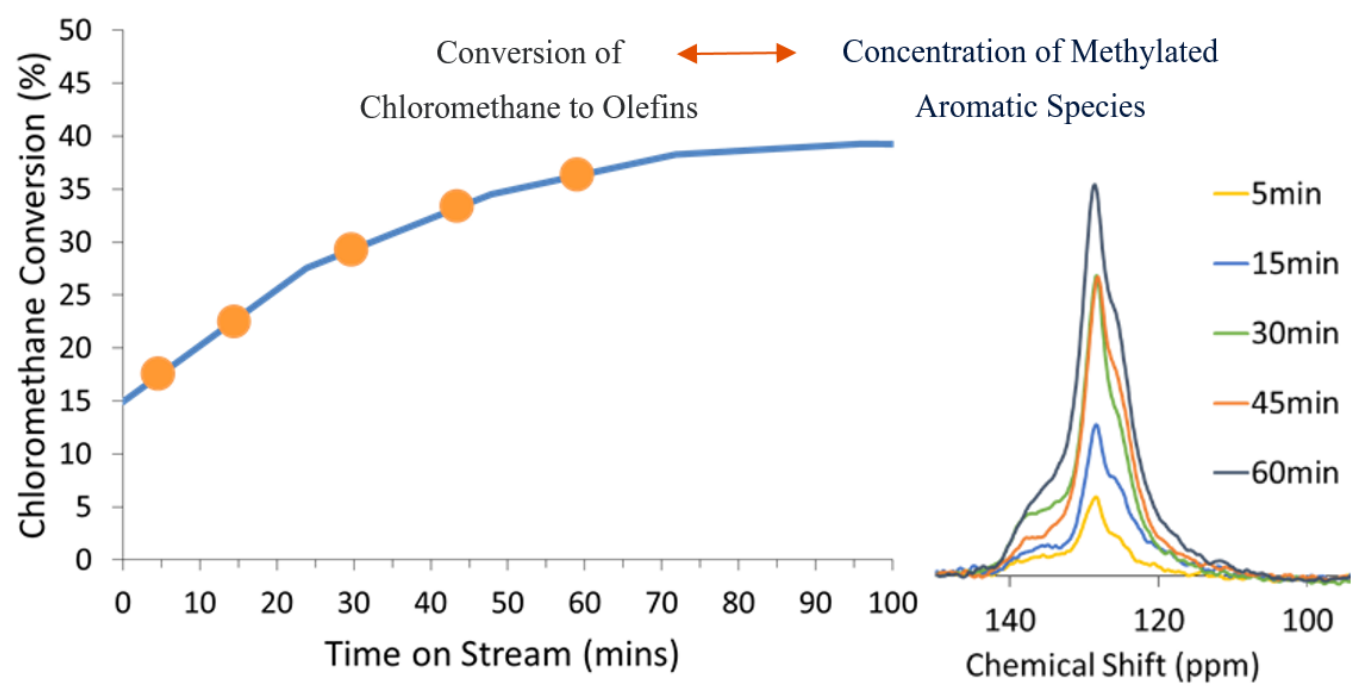

\section{Keywords}

SAPO-34, Hydrocarbon Pool, Chloromethane, Induction period, ${ }^{13} \mathrm{C}-\mathrm{NMR}$ 


\section{Introduction}

The increasing availability of natural gas resources, especially shale gas, has motivated numerous efforts to develop commercial processes for producing chemicals from methane $[1,2]$. The abundance of methane reserves can potentially lead to commercially viable utilization of this greenhouse gas in the chemical industry. Methane is predominantly used for production of syngas/hydrogen via steam reforming [3]. Higher hydrocarbons can be produced from syngas in the Fisher-Trøpsch reaction [4]. However, this route leads to a wide product distribution [5]. Hence, routes that are more selective towards valuable light olefins (ethylene and propylene) are more desirable [6].

The methanol-to-olefins (MTO) process may provide a sharper product distribution with higher selectivity towards light olefins [7]. Previous reports have suggested that silicoaluminophophates such as SAPO-34 are commercial catalysts for the MTO process [2,7-9].

An alternative integrated route involves the conversion of methane to methyl halides and subsequent transformation of methyl halides to light olefins [10]. Among the methyl halides, chloromethane (also known as methyl chloride) has been studied the most for this purpose [11]. The first step, which involves the production of chloromethane from methane, can be accomplished using a number of different routes. The second step, which involves conversion of chloromethane to light olefins, proceeds over a zeolite/molecular sieve catalyst. For this step, SAPO-34 has been shown to be highly selective towards light olefins [10].

The conversion of methanol to olefins over SAPO-34 catalysts has been suggested to proceed through a 'hydrocarbon pool' mechanism [7]. This mechanism was introduced by Dahl and Kolboe in the 1990s $[12,13]$. The chloromethane-to-olefins (CTO) transformation appears to proceed through a similar mechanism whereby the reactant molecules lead to formation of 'organic centers' within the microporous cages of SAPO-34 [11]. Other CTO literature over ZSM-5 also propose a similar hydrocarbon pool mechanism [14]. It has been suggested that these organic centers consist of polymethylated benzene molecules. Studies on this topic in the CTO literature have provided indirect correlations mostly through analysis of completely spent catalyst [15]. The formation of light olefins - especially ethylene may occur via the reaction of additional reactant molecules with the methylated benzene species that are located within the SAPO-34 cages [16-18]. Due to the nature of this mechanism, the MTO reaction has shown an induction/autocatalysis period during the initial stages of the reaction [19]. Similarly, through our experiments we have observed a pronounced induction period at the onset of the CTO reaction over SAPO-34. It is believed that the organic component of the active centers forms during this 
period. In this paper, we report a direct correlation between the chloromethane conversion/light olefin yield and the relative increase in the amount of methylated benzene species formed within the SAPO-34 cages using a variety of techniques, including ex situ ${ }^{13} \mathrm{C}$-solid state nuclear magnetic resonance (NMR) analysis.

\section{Experimental Methods}

\subsection{Catalyst Synthesis}

SAPO-34 was synthesized using a hydrothermal synthesis method. The molar ratios of reagents used were: $2 \mathrm{TEAOH}: 0.4 \mathrm{SiO}_{2}: 1 \mathrm{Al}_{2} \mathrm{O}_{3}: 1 \mathrm{P}_{2} \mathrm{O}_{5}: 60 \mathrm{H}_{2} \mathrm{O}$. An aqueous solution of $85 \% \mathrm{H}_{3} \mathrm{PO}_{4}$ (Sigma-Aldrich) was made. Aluminum isopropoxide (98\%, Sigma-Aldrich) was subsequently added over a period of 30 minutes while the solution was stirred continuously, and the slurry was stirred for an additional hour. Ludox AS-40 (Sigma-Aldrich) and tetraethylammonium hydroxide (TEAOH) (35\%, ZeoGen) were added drop-wise, and the mixture was stirred for 30 minutes following addition of each of these structuredirecting reagents. The resulting synthesis solution was transferred to a $300 \mathrm{~mL}$ Teflon-lined autoclave unit and treated at $190^{\circ} \mathrm{C}$ for 24 hours. The product was washed three times with de-ionized water. The solid was separated from the mother liquor by centrifugation, dried at $90^{\circ} \mathrm{C}$ overnight and then calcined at $550^{\circ} \mathrm{C}$ for 8 hours. The resulting $(\mathrm{Al}+\mathrm{P}) / \mathrm{Si}$ ratio of the formed crystallites is 9.7.

\subsection{Catalytic Tests}

Catalytic tests were carried out using a fixed-bed reactor system. The reactor unit consisted of a 0.5inchdiameter stainless steel reactor. One gram of catalyst (40-60 mesh) was diluted with silicon carbide (1835 mesh) and was loaded into the heated zone of the furnace. The catalyst bed length was kept between 5 and $6 \mathrm{~cm}$. The reactor was heated to $200^{\circ} \mathrm{C}$ in the presence of nitrogen flow for $1-2$ hours in order to dry the catalyst. The reactor temperature was then increased to $350^{\circ} \mathrm{C}$, and then the feed gas was switched to a $20 \%{ }^{13} \mathrm{CH}_{3} \mathrm{Cl} / \mathrm{N}_{2}$ mixture. The total flow rate was held at $74 \mathrm{sccm}$ in order to achieve a weight-hourly space velocity (WHSV) of $2 / \mathrm{hr}$. The reactions were carried out for $5,15,30,45$ or 60 minutes. Following reaction, the reactor was flushed with $\mathrm{N}_{2}$ and cooled to room temperature. The spent catalysts were separated from the silicon carbide diluent by sieving. These samples were then subjected to ${ }^{13} \mathrm{C}$-solid state NMR.

In another set of experiments, similar tests were carried out at $450{ }^{\circ} \mathrm{C}$ with $20 \%{ }^{12} \mathrm{CH}_{3} \mathrm{Cl} / \mathrm{N}_{2}$ as the feed mixture. The total flow rate was held at $110.9 \mathrm{sccm}$ to achieve a WHSV of $3 / \mathrm{hr}$. The reaction durations were 15 minutes, 45 minutes, 2 hours and 8 hours. The spent catalysts were separated from the silicon 
carbide. Micropore volume measurements were performed on these spent catalyst samples to estimate the fraction of the SAPO-34 cages occupied by coke species for different times on stream.

\subsection{Catalyst Characterization}

The in situ characterization of SAPO-34 was performed in a batch reactor equipped with a Fourier transform infrared (FTIR) spectrometer, in order to monitor the real-time concentrations of gas-phase species, as well as the buildup of surface species on the catalyst. FTIR spectra were recorded with $4 \mathrm{~cm}^{-1}$ resolution using a Thermo Nicolet Nexus 470 spectrometer equipped with a mercury cadmium telluride (MCT-A) detector. Details of the cell and the sample preparation procedures have been reported previously [20]. Prior to performing the chloromethane-to-olefins (CTO) reaction, the SAPO-34 catalyst (17.4 $\mathrm{mg}$, which was pressed on a tungsten mesh suspended within the reactor) was heated to $500^{\circ} \mathrm{C}$ at a rate of $15^{\circ} \mathrm{C} / \mathrm{min}$ for degassing under vacuum conditions. After pre-treatment, the catalyst was held at $500^{\circ} \mathrm{C}$, and then chloromethane was introduced into the reaction vessel at a pressure of 8.0 Torr. During the reaction, the concentrations of gaseous species $\left(\mathrm{CH}_{3} \mathrm{Cl}\right.$, olefins and $\left.\mathrm{CO}_{2}\right)$ were monitored by recording FTIR spectra (average of 32 scans) every 15 seconds. After 30 minutes of reaction, the chamber was evacuated, and then a surface scan was collected. Five experimental runs were performed consecutively using the same catalyst sample (degassing was completed only prior to the first run). For the first three runs, the chloromethane pressure was 8.0 Torr and the reaction time was $30 \mathrm{~min}$; for runs 4 and 5, the pressure was increased to 16.0 Torr and the reaction time was extended to $60 \mathrm{~min}$. All other experimental conditions remained constant.

The nitrogen physisorption/micropore analyses were performed with a Micromeritics ASAP 2020 instrument. Prior to the measurements, the catalyst samples were degassed (evacuated) at $250^{\circ} \mathrm{C}$ for 6 hours. The micropore volumes were estimated over the $\mathrm{P} / \mathrm{P}_{\mathrm{o}}$ range of $0-10^{-3}$. An equilibration delay of 60 seconds was used for each data point. The micropore volumes were estimated using the 'alpha-s' method, wherein non-porous silica was used as a reference [21].

The ex situ ${ }^{13} \mathrm{C}$-solid state NMR experiments were performed at Spectral Data Services (Champaign, IL). These experiments were performed in the cross polarization magic angle spinning (CP-MAS) mode, using a Tecmag console with a Doty Scientific $7 \mathrm{~mm}$ XC CP-MAS probe. The CP-MAS experiment used a 1 milisecond contact time with a 50 microsecond interrupted decoupling delay. The ${ }^{13} \mathrm{C}$ Larmor frequency was $91.2695 \mathrm{MHz}$ and the ${ }^{1} \mathrm{H}$ frequency was $363.33 \mathrm{MHz}$. Total 4500 scans were collected for each sample, with a pulse delay of 3.2 seconds. 


\section{Results and Discussion}

In the present analysis, we use the following three different sets of experimental conditions. Each of which is used for a different purpose. The data obtained at each of these conditions is not directly compared across different conditions. However, the knowledge gained through each of the individual experiments, such as theory and mechanisms, is translated across the different conditions, since this is taken as a constant commonality for a chloromethane to olefins reaction.

1) $C^{13}$-NMR analysis (Figures 3-6) has been used to obtain a direct correlation between the catalyst activity during the activation period and concentration of certain organic species in the catalyst.

2) In situ FTIR experiments were performed in order to identify the class of carbon species initially being formed in the catalyst in the chloromethane to olefins reaction. This was why a batch reactor was used with very low exposures of chloromethane.

3) Micropore analysis was performed in order to identify whether the preferred location of organic species is inside or outside the pores of the SAPO-34 catalyst. The samples obtained for such an analysis was performed at higher temperatures in order to accelerate the formation of organic species.

The deactivation of SAPO-34 in the CTO reaction occurs fairly rapidly, as has been shown in the past and can be seen in Figure 1. The cause of the deactivation can be resolved by analyzing the micropore volume and carbon level of the spent catalyst throughout the course of the reaction; these values are provided in Table 1. The percent of cages filled given in Table 1 refer to the loss in micropore volume compared to the micropore volume of the fresh catalyst, which is calculated by dividing the micropore volume of a given catalyst by that of the fresh catalyst. By correlating the data in Table 1 to the activity curve shown in Figure 1, it becomes apparent that the cause of the catalyst deactivation is a rapid loss in micropore volume along with a rise in the carbon level of the catalyst during the reaction. The carbon accumulated in the cages of the SAPO-34 structure blocks access to the catalyst active sites and restricts chloromethane from entering the catalyst pore structure.

One of the surprising implications of this analysis is that even at short times on stream and low coke levels, i.e. 15 minutes, the SAPO-34 catalyst has lost an appreciable amount of its internal volume. As can be seen in Figure 1, the catalyst goes through an initial activation period where the activity increases to its maximum. This result may indicate that the structure of the catalyst changes during the reaction. This period before the maximum conversion level is achieved could be attributed alternatively to the buildup of some species on the catalyst, initially inhibiting the reaction. 
A catalytic reaction will have an activation period when the active site for the reaction is not present in the fresh catalyst; the catalyst must be altered in order to become active for the reaction. This change could be a physical change, reduction or oxidation of a metal or active component, or selective poisoning [22,23]. In the MTO literature, a similar, albeit much shorter, activation period has been observed [24]. Researchers have shown that the activation period occurring during the initial stages of the MTO is due to the buildup of alkylaromatic species [25]. These species have been theorized to be hexamethylbenzenes and serve as the active sites in the 'hydrocarbon pool' mechanism $[18,25,26]$.

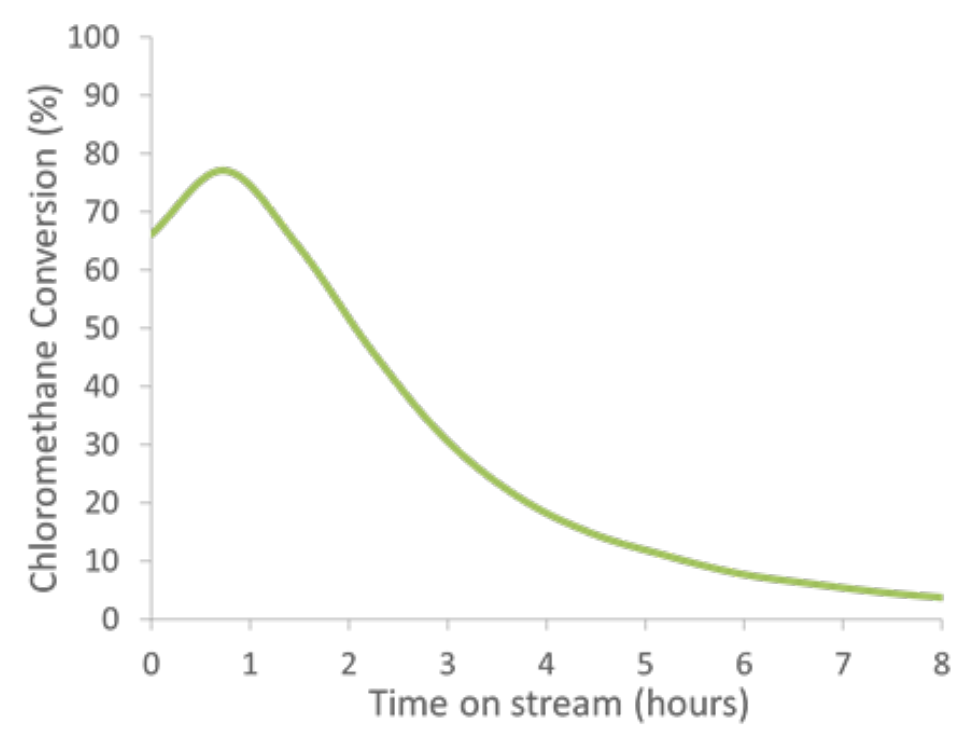

Figure 1: Chloromethane conversion vs. time on stream for SAPO-34 catalyst. $T=450^{\circ} \mathrm{C}$. WHSV $=3 / \mathrm{hr} .1$ atm. Feed $=20$ vol\% chloromethane $\left({ }^{12} \mathrm{CH}_{3} \mathrm{Cl}\right)$ in $\mathrm{N}_{2}$.

Table 1: Micropore volume (cc/g) and carbon level within spent catalyst over the course of the chloromethane to olefins reaction. $T=450^{\circ} \mathrm{C}$. WHSV $=3 / \mathrm{hr} .1 \mathrm{~atm}$. Feed $=20$ vol\% chloromethane $\left({ }^{12} \mathrm{CH}_{3} \mathrm{Cl}\right)$ in $\mathrm{N}_{2}$.

\begin{tabular}{lccc}
\hline & $\begin{array}{c}\text { Micropore Volume } \\
\text { (cc/g) }\end{array}$ & wt\% C & $\begin{array}{c}\text { \% of cages } \\
\text { filled }\end{array}$ \\
\hline Fresh & 0.23 & $0.0 \%$ & $0.0 \%$ \\
15 minutes & 0.19 & $1.0 \%$ & $17.4 \%$ \\
45 minutes & 0.17 & $2.6 \%$ & $26.1 \%$ \\
2 hours & 0.12 & $5.5 \%$ & $47.8 \%$ \\
8 hours & 0.04 & $11.8 \%$ & $82.6 \%$ \\
\hline
\end{tabular}


In order to elucidate whether a similar hydrocarbon pool mechanism occurs during the CTO reaction, the type of carbon species being formed during the early stages of the reaction must be identified and the formation rate of this carbon species must be correlated to the activation period of the catalyst. A batch reactor with in situ FTIR capabilities was used to probe the first stages of the CTO reaction. The FTIR scans for the region 2700-3100 $\mathrm{cm}^{-1}$ are shown in Figure 2.

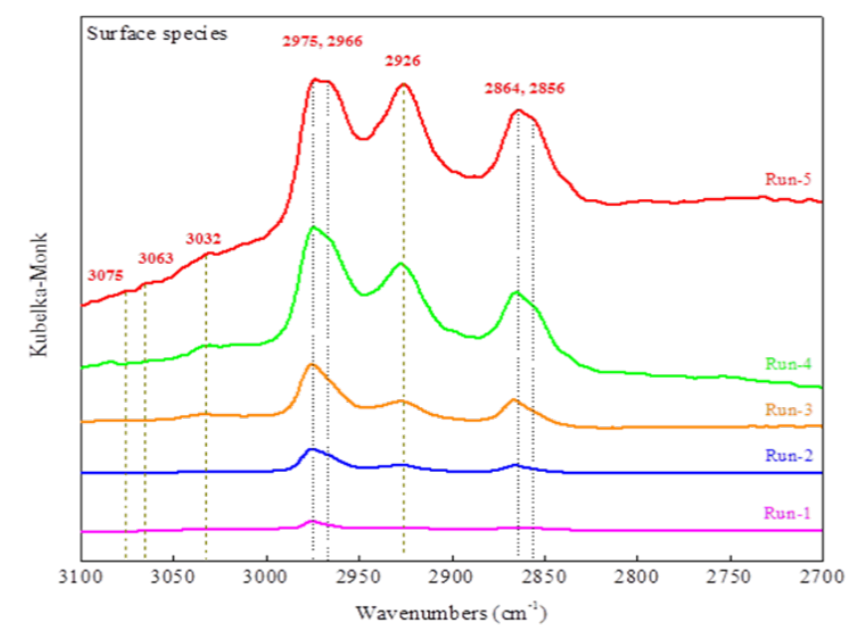

Figure 2: FTIR spectra taken of SAPO-34 after exposure to chloromethane $\left({ }^{12} \mathrm{CH}_{3} \mathrm{Cl}\right)$ at $500^{\circ} \mathrm{C}$ for a set period of time. For the runs 1-3, the chloromethane pressure was 8.0 Torr and the reaction time was 30 min; for runs 4 and 5, the pressure was increased to 16.0 Torr and the reaction time was extended to 60 min. Experimental details are discussed in the experimental section.

FTIR peaks at 2864 and $2975 \mathrm{~cm}^{-1}$ were assigned to methyl stretching modes for $\mathrm{CH}_{3} \mathrm{O}-\mathrm{Al}$ [27]. FTIR peaks at 2856 and $2966 \mathrm{~cm}^{-1}$ were assigned to methyl stretching modes for $\mathrm{CH}_{3} \mathrm{O}-\mathrm{Si}$ [27]. The peaks at 2926, 3032,3063 , and $3075 \mathrm{~cm}^{-1}$ were assigned to aromatic species (benzene or poly-alkylated benzene species) $[28,29]$.

As shown in Figure 2, the first scan taken after Run-1 only shows peaks associated with methyl stretching modes on a Brønsted acid site. This may indicate that the first step in the CTO reaction mechanism consists of cleaving the chlorine from chloromethane on the Brønsted acid site to form $\mathrm{HCl}$, and leaving a methyl species attached to the Brønsted acid site. As the reaction proceeds in Run-2, the methyl stretching modes increase in intensity and a peak associated with aromatic species appears at $2926 \mathrm{~cm}^{-1}$. Since the aromatic species signature is not visible in the first scan, an appreciable amount of 
methyl species may need to be generated in order for the methyl species to cyclize into an aromatic species. After Run-2, a new methyl stretching mode arises around $2860 \mathrm{~cm}^{-1}$, indicating that more methyl species have been generated and validating this argument. As the SAPO-34 catalyst proceeds through Runs 3-5, both the methyl stretching modes and the stretching modes associated with aromatic species increase in intensity.

The gradual appearance of an aromatic species in these FTIR spectra supports the hypothesis that an aromatic species is formed in the early stages of the reaction. From the micropore analysis, this aromatic carbon species is observed to be internal to the SAPO-34 structure. In order to confirm whether this species might be the part of the active site for the СTO reaction, the formation rate of this carbon species must be correlated to the catalyst activity during the activation period of the reaction. In order to examine this relationship, the SAPO-34 catalyst was reacted with ${ }^{13} \mathrm{C}$-chloromethane and the catalyst was removed at various points in time during the activation period of the reaction. An ex situ CP-MAS ${ }^{13} \mathrm{C}-\mathrm{NMR}$ analysis was used to investigate the retained carbon species in the SAPO-34 structure. In order to have a sufficient number of samples from the activation period, the reaction was slowed down and the activation period extended by decreasing the reaction temperature to $350^{\circ} \mathrm{C}$. As a result, the duration of the activation period was increased to approximately 90-100 minutes, as shown in Figure 3. Figure 4 shows the precise points during the activation period when catalyst samples were removed. In total, the catalyst was sampled at five points during the activation period, at 5, 15, 30, 45, and 60 minutes time on stream.

The product distribution shown in Figure 3 is consistent with what has been reported in the MTO literature [30]. During the initial stages of the reaction, propylene formation has been suggested to occur through the alkene methylation cycle, while ethylene is a product of the aromatic cycle. In our experiment, we have intentionally slowed the formation of the aromatic species that are active for the aromatic cycle. Thus, we believe that the alkene methylation cycle dominates at the conditions used in Figure 3 and results in the propylene selectivity being higher than the ethylene selectivity. It has been shown in a variety of MTO and CTO reports that the propylene/ethylene ratio in the product stream is highly dependent on the reaction temperature $[15,31]$.

CP-MAS ${ }^{13} \mathrm{C}-\mathrm{NMR}$ is a highly sensitive technique that can be used to identify the types of carbon species that are formed during the activation period of the CTO reaction [25]. The CP-MAS ${ }^{13} \mathrm{C}-\mathrm{NMR}$ spectra of the SAPO-34 catalyst after reacting with ${ }^{13} \mathrm{C}$-chloromethane for different periods of time are shown in Figure 5. 


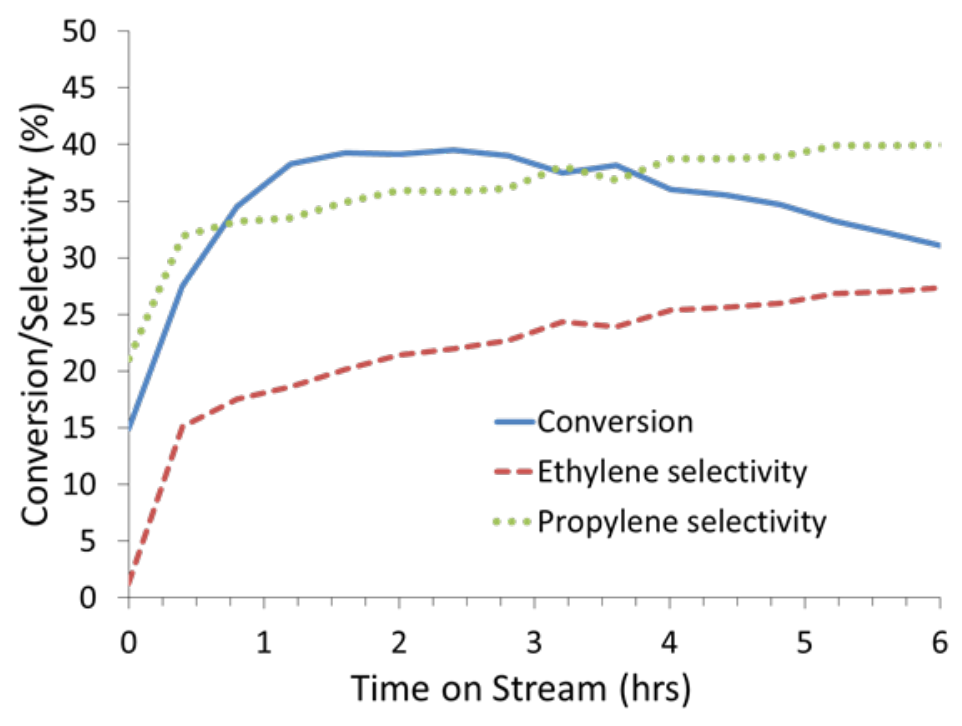

Figure 3: Chloromethane conversion and selectivity to ethylene and propylene as a function of time on stream for SAPO-34 at $350^{\circ} \mathrm{C}$. WHSV $=2 / \mathrm{hr} .1 \mathrm{~atm} .20 \mathrm{vol} \%{ }^{13} \mathrm{C}$-chloromethane in $\mathrm{N}_{2}$.

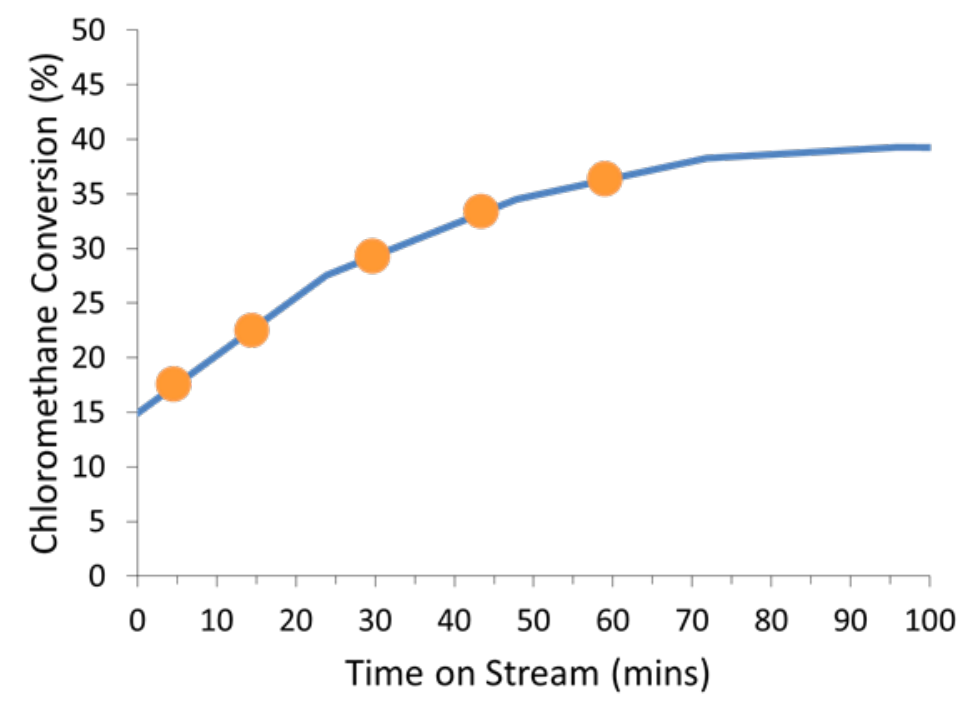

Figure 4: Chloromethane conversion vs. time on stream. The filled circles indicate the precise times at which catalyst was removed during the activation period and analyzed by $C P-M A S^{13} \mathrm{C}-N M R$. T $=350^{\circ} \mathrm{C}$. WHSV $=2 / \mathrm{hr} .1 \mathrm{~atm} .20$ vol\% ${ }^{13} \mathrm{C}$-chloromethane in $\mathrm{N}_{2}$. 


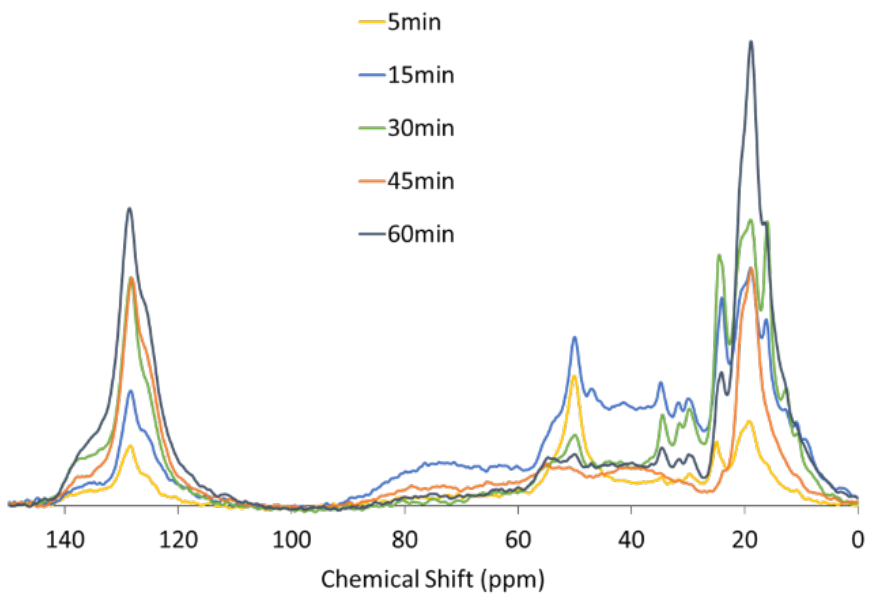

Figure 5: CP-MAS ${ }^{13} \mathrm{C}-\mathrm{NMR}$ spectra of SAPO-34 taken at different points in time during the activation period in the chloromethane to olefins reaction.

In Figure 5, the peak in the region of $130 \mathrm{ppm}$ is assigned to aromatic species [32-34]. The appearance of this peak is consistent with past MTO literature, where the species associated with it have been determined to be the part of the active site for the hydrocarbon pool mechanism [34]. The peak in the region of $20 \mathrm{ppm}$ has been assigned to methyl groups on an aromatic species [33,34]. It can be seen that for the spectrum collected at 30 minutes there are three peaks in the region close to $20 \mathrm{ppm}$. This peaks appears to be modified into a single peak for the 45 minutes spectrum. These changes likely occur due to various levels of methylation on the aromatic species as a function of time on stream. From Figure 5, it can be seen that the intensity of the peaks at $20 \mathrm{ppm}$ and $130 \mathrm{ppm}$ increase as a function of time during the activation period of the reaction. Interpolating the data, this growth can be attributed to polymethylated aromatic species populating the cages, i.e. increasing in concentration and number, within SAPO-34 during the activation period. The increase in intensity of these peaks can be correlated directly to the increase in activity during the activation period of the reaction, which is shown in Figures 3 and 4 . This correlation provides evidence that a polymethylated aromatic species is responsible for the rise in activity during the early stages of the reaction. A better illustration of this correlation is shown in Figure 6. 


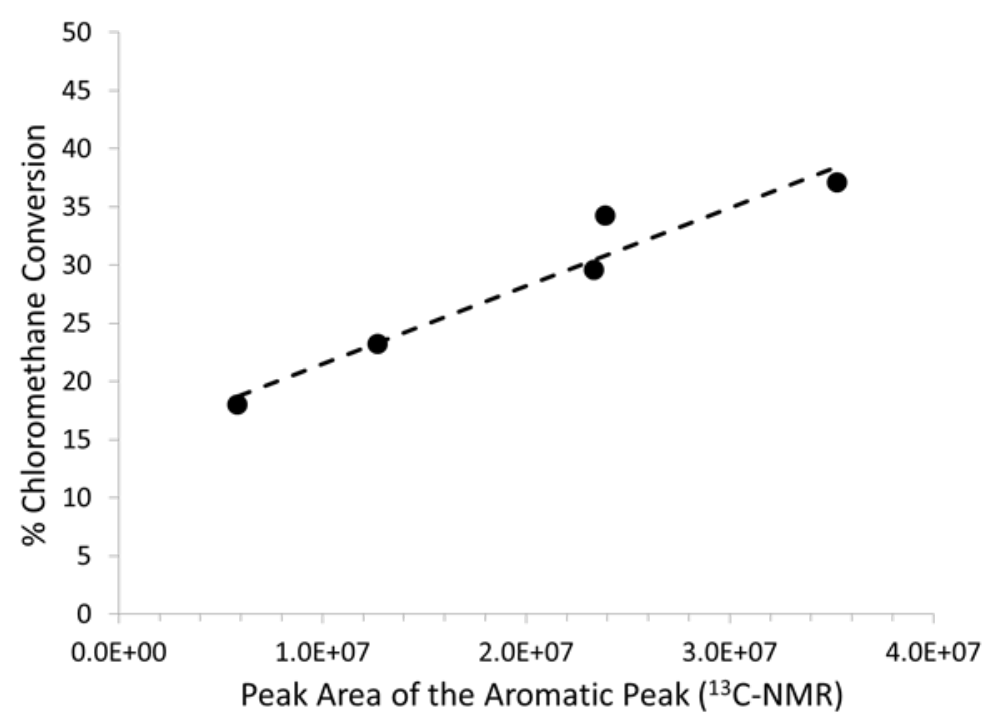

Figure 6: Correlation between the chloromethane conversion shown in Figure 4, and the area of the peak assigned to an aromatic species from CP-MAS ${ }^{13} C-N M R$ spectra of SAPO-34 shown in Figure 5 (130 ppm).

The peaks at approximately $50 \mathrm{ppm}$ in Figure 5 can be assigned to the methyl species on a Brønsted acid site [35]. This peak effectively correlates the NMR spectra with the FTIR spectra that were shown earlier. Interestingly, these peaks increase in intensity through 15 minutes on stream, but decrease in intensity from 30 minutes onwards. These methyl species are likely the building blocks for the aromatic species of the hydrocarbon pool. In the initial stages of the reaction, the concentration of these methyl species is increases until a critical concentration is reached, after which, cyclization into aromatic species may occur. Once the concentration of aromatic species in the cages begins to increase, the concentration of these aliphatic species would decrease, since they are likely to be transient intermediates in the growth mechanism of aromatics. This theory is supported by the data in Figure 5: The intensity of the peak at 50 ppm decreases from 30 minutes onwards, while the intensity of the aromatic peak at 130 ppm generally increases with time. However, we acknowledge that the specific role of these methyl species has been highly debatable within the MTO literature, especially, towards the formation of the first carbon-carbon bond for the hydrocarbon pool, and the occurrence of these methyl species appears to be dependent on the applied reaction conditions [36-38].

Since FTIR and CP-MAS ${ }^{13}$ C-NMR analyses (shown in Figures 3-6) have confirmed that a polymethylated aromatic species is formed in the cages of SAPO-34 during the activation period, this implies that the reaction most likely proceeds through the hydrocarbon pool mechanism. With this knowledge we can now apply this theory to the same reaction occurring at different experimental conditions, where the induction period is much shorter and more difficult to study. One example of this is that an interesting 
analysis can now be done using the micropore and residual carbon data of SAPO-34, which is shown in Table 1. Using these data and assuming that the polymethylated aromatic species is hexamethylbenzene (HMB), which is consistent with the proposed hydrocarbon pool mechanism, then we can calculate the theoretical number of HMB species in the SAPO-34 structure $[39,26]$. This analysis would only be valid for when HMB is the predominant species in the cages, which occurs at the end of the activation period, i.e. 45 minutes on stream according to Figure 1. Before this point in time, there is likely to be a mixture of aromatic species along with the intermediates that participate in the aromatic formation mechanism. During the deactivation period, i.e. after the activation period, polyaromatic growth may occur, which ultimately would cause catalyst deactivation. Thus, there should be a mixture of aromatic and polyaromatic species during this period of time [32].

By taking the standard unit cell volume of $\mathrm{CHA}(13.8 \AA \AA \times 13.8 \AA \AA$ x $15.07 \AA ̊)$, the number of cages in a unit cell of CHA (6 cages per unit cell [40]), and the micropore volume of our fresh SAPO-34 catalyst (0.23 $\mathrm{cc} / \mathrm{g}$ ), the theoretical number of cages per gram of SAPO-34 can be calculated. Converting the weight\% of carbon from Table 1 to moles of $\mathrm{HMB}\left(\mathrm{C}_{12}\right)$, the moles of $\mathrm{HMB}$ can be divided by the number of cages per gram of SAPO-34 to attain the theoretical percentage of cages filled by HMB species. This calculation yields that approximately $22.3 \%$ of the SAPO-34 cages are likely to be filled by HMB. This number is surprisingly close to the loss in micropore volume at this point in time, i.e. $26.1 \%$, as shown in Table 1. Although a few assumptions have been made in order to arrive at the percentage of cages filled with $\mathrm{HMB}$, the close correspondence to the actual percent loss in micropore volume reinforces the possibility that hexamethylbenzene is the active site in the CTO reaction.

The final point to consider in the lifetime of the CTO catalyst, for which a similar analysis to that described above can be applied, is at complete or near-complete deactivation. At this point, the polyaromatic species - which cause the deactivation of SAPO-34 - will have transformed into the largest allowable polyaromatic species in the CHA cage, which is pyrene $[2,41]$. At 8 hours of time on stream, as shown in Figure 1, the SAPO-34 catalyst is near full deactivation. Applying the above analysis to this point in time, the percentage of cages occupied by pyrene molecules $\left(C_{16}\right)$ is $84.3 \%$. This calculated value is remarkably close to the actual percent loss in micropore volume at 8 hours, $82.6 \%$ (Table 1). The concordance between these numbers supports the theory that deactivation is caused by the growth of polyaromatic species within the SAPO-34 cages [21]. 


\section{Conclusion}

A clear activation period has been identified in the chloromethane-to-olefins (CTO) reaction over SAPO34. In order to optimize a catalyst for the reaction, the transformations that occur during the activation period must be understood. Using a combination of reactor data, micropore volume analysis, in situ FTIR studies, and CP-MAS ${ }^{13} \mathrm{C}-\mathrm{NMR}$ data, we have provided a description of these transformations. The micropore volume analysis shows that the carbon species that are generated in the CTO reaction are internal in the SAPO-34 framework and cause the loss in micropore volume that ultimately leads to catalyst deactivation. Using a batch reactor equipped with in situ FTIR to study the formation of these carbon species at low partial pressures of chloromethane, the early periods of the reaction was probed in order to observe the carbon species that form initially within SAPO-34. The first peaks to arise in the FTIR spectra correspond to methyl stretching modes on Brønsted acid sites. Later in the activation period, increasing exposure of the catalyst to chloromethane produced peaks related to benzene or polyalkylated benzene species. Over successive exposure of the catalyst to chloromethane, the peaks related to these aromatic species increased in intensity. In order to directly correlate the growth of these aromatic species to the increasing activity observed during the activation period, the reaction was slowed down to elongate the activation period. The catalyst was removed at various points during the activation period and analyzed using ex situ CP-MAS ${ }^{13} \mathrm{C}-\mathrm{NMR}$. The NMR spectra showed peaks consistent with a polymethylated benzene species, and these peaks were correlated to the activity data obtained during the activation period. This correlation provides direct evidence that a polymethylated benzene species retained within the cages of SAPO-34 may be responsible for the increase in activity during the activation period of the reaction. This is the first known report identifying a direct semiquantitative correlation between the catalyst activity and growth of a methylated benzene active species, during the activation period of the chloromethane to olefins reaction. Finally, this analysis shows that the catalyst activation mechanism for the CTO reaction is consistent with the results obtained for the methanol to olefins reaction and the hydrocarbon pool mechanism [7]. 


\section{Acknowledgement}

The authors would like to thank Prof. Daniel Shantz (Tulane University) for the micropore analysis. The authors acknowledge Prof. James Haw (University of Southern California) for helpful discussions

regarding the ${ }^{13} \mathrm{C}-\mathrm{NMR}$ technique. The authors would like to thank Dr. Scott Mitchell (SABIC) for insightful scientific discussions and inputs. The authors are thankful to Dr. Dhaval Shah and SABIC for the permission to publish this article. 


\section{References}

[1] L.A. Noronha, E.F. Souza-Aguiar, C.J.A. Mota, Catal. Today 101 (2005) 9-13.

[2] Y. Wei, D. Zhang, F. Chang, Q. Xia, B.-L. Su, Z. Liu, Chem. Commun. (2009) 5999-6001.

[3] J. Xu, G.F. Froment, AIChE J. 35 (1989) 88-96.

[4] J. Yang, W. Ma, D. Chen, A. Holmen, B.H. Davis, Appl. Catal. Gen. 470 (2014) 250-260.

[5] I. Puskas, R.S. Hurlbut, Catal. Today 84 (2003) 99-109.

[6] F. Jiao, J. Li, X. Pan, J. Xiao, H. Li, H. Ma, M. Wei, Y. Pan, Z. Zhou, M. Li, S. Miao, J. Li, Y. Zhu, D. Xiao, T. He, J. Yang, F. Qi, Q. Fu, X. Bao, Science 351 (2016) 1065-1068.

[7] P. Tian, Y. Wei, M. Ye, Z. Liu, ACS Catal. 5 (2015) 1922-1938.

[8] S. Xu, A. Zheng, Y. Wei, J. Chen, J. Li, Y. Chu, M. Zhang, Q. Wang, Y. Zhou, J. Wang, F. Deng, Z. Liu, Angew. Chem. Int. Ed. 52 (2013) 11564-11568.

[9] S. Wilson, P. Barger, Microporous Mesoporous Mater. 29 (1999) 117-126.

[10] S. Svelle, S. Aravinthan, M. Bjørgen, K.-P. Lillerud, S. Kolboe, I.M. Dahl, U. Olsbye, J. Catal. 241 (2006) 243-254.

[11] L. Kong, B. Shen, J. Zhao, J. Liu, Ind. Eng. Chem. Res. 53 (2014) 16324-16331.

[12] I.M. Dahl, S. Kolboe, Catal. Lett. 20 (1993) 329-336.

[13] I.M. Dahl, S. Kolboe, J. Catal. 149 (1994) 458-464.

[14] M. Ibáñez, M. Gamero, J. Ruiz-Martínez, B.M. Weckhuysen, A.T. Aguayo, J. Bilbao, P. Castaño, Catal. Sci. Technol. 6 (2015) 296-306.

[15] U. Olsbye, O.V. Saure, N.B. Muddada, S. Bordiga, C. Lamberti, M.H. Nilsen, K.P. Lillerud, S. Svelle, Catal. Today 171 (2011) 211-220.

[16] K. Hemelsoet, J. Van der Mynsbrugge, K. De Wispelaere, M. Waroquier, V. Van Speybroeck, ChemPhysChem 14 (2013) 1526-1545.

[17] M. Stöcker, Microporous Mesoporous Mater. 29 (1999) 3-48.

[18] U. Olsbye, S. Svelle, M. Bjørgen, P. Beato, T.V.W. Janssens, F. Joensen, S. Bordiga, K.P. Lillerud, Angew. Chem. Int. Ed. 51 (2012) 5810-5831.

[19] K.Y. Lee, H.-J. Chae, S.-Y. Jeong, G. Seo, Appl. Catal. Gen. 369 (2009) 60-66.

[20] W.W. Lonergan, D.G. Vlachos, J.G. Chen, J. Catal. 271 (2010) 239-250.

[21] H. Kral, J. Rouquerol, K.S.W. Sing, K.K. Unger, Characterization of Porous Solids, Elsevier, 1988.

[22] M. Kobayashi, T. Kanno, J. Catal. 90 (1984) 24-31.

[23] D.Y. Murzin, T. Salmi, Catalytic Kinetics: Chemistry and Engineering, Elsevier, 2016.

[24] L. Qi, Y. Wei, L. Xu, Z. Liu, ACS Catal. 5 (2015) 3973-3982. 
[25] W. Song, J.F. Haw, J.B. Nicholas, C.S. Heneghan, J. Am. Chem. Soc. 122 (2000) 10726-10727.

[26] J.F. Haw, D.M. Marcus, Top. Catal. 34 (2005) 41-48.

[27] T.R. Forester, R.F. Howe, J. Am. Chem. Soc. 109 (1987) 5076-5082.

[28] J. Eng, B.E. Bent, B. Frühberger, J.G. Chen, J. Phys. Chem. B 101 (1997) 4044-4054.

[29] J. Eng, J.G. Chen, I.M. Abdelrehim, T.E. Madey, J. Phys. Chem. B 102 (1998) 9687-9696.

[30] S. Ilias, A. Bhan, ACS Catal. 3 (2013) 18-31.

[31] Y. Wei, D. Zhang, Z. Liu, B.-L. Su, J. Catal. 238 (2006) 46-57.

[32] J.F. Haw, W. Song, D.M. Marcus, J.B. Nicholas, Acc. Chem. Res. 36 (2003) 317-326.

[33] M. Hunger, M. Seiler, A. Buchholz, Catal. Lett. 74 (2001) 61-68.

[34] Y. Jiang, J. Huang, V.R. Reddy Marthala, Y.S. Ooi, J. Weitkamp, M. Hunger, Microporous Mesoporous Mater. 105 (2007) 132-139.

[35] F. Salehirad, M.W. Anderson, J. Catal. 164 (1996) 301-314.

[36] R.Y. Brogaard, R. Henry, Y. Schuurman, A.J. Medford, P.G. Moses, P. Beato, S. Svelle, J.K. Nørskov, U. Olsbye, J. Catal. 314 (2014) 159-169.

[37] K.D. Wispelaere, S. Bailleul, V.V. Speybroeck, Catal. Sci. Technol. 6 (2016) 2686-2705.

[38] A.J. Jones, E. Iglesia, Angew. Chem. Int. Ed. 53 (2014) 12177-12181.

[39] F. Bleken, M. Bjørgen, L. Palumbo, S. Bordiga, S. Svelle, K.-P. Lillerud, U. Olsbye, Top. Catal. 52 (2009) 218-228.

[40] R. Krishna, J.M. van Baten, Phys. Chem. Chem. Phys. 15 (2013) 7994-8016.

[41] M. Zokaie, D.S. Wragg, A. Grønvold, T. Fuglerud, J.H. Cavka, K.P. Lillerud, O. Swang, Microporous Mesoporous Mater. 165 (2013) 1-5. 